\title{
Umbilical Cord-derived Mesenchymal Stem Cells with Surfactant Protein B Alleviates Inflammatory Response in Acute Respiratory Distress Syndrome by Regulating Macrophage Polarization
}

\author{
Hongtao Xu๑, Guoming Nie®, Taiyong Yin®, Cui Shao®, Dongsheng Ding®, Minshu Zou®
}

Department of Pediatrics, General Hospital of Central Theater Command of Chinese People's Liberation Army, Wuhan, China

Background: Acute respiratory distress syndrome (ARDS) is a severe disorder that is related to a high mortality. Mesenchymal stem cells (MSCs) have shown strong effects in relieving lung injury.

Aims: To determine the role of umbilical cord-derived MSCs (UC-MSCs) together with surfactant protein B (SP-B) in ARDS.

Study Design: Animal experimentation.

Methods: Immunophenotypic characteristics of UC-MSCs were identified. BALB/c mice were intratracheally administrated with lipopolysaccharide (LPS) and received UC-MSCs or UC-MSCs transfected with SP-B (UC-MSCs-SP-B). Pathological changes and lung injury degrees after transplantation were assessed by histological and biochemical analyses. Inflammatory chemokine and cytokine production in the bronchoalveolar lavage fluid (BALF) was measured using enzyme-linked immunoassay. Flow cytometry was used to examine macrophage phenotypes and differentiation of T-helper 17 (Th17) and T-regulatory (Treg) in the BALF.

Results: Our results showed that isolated UC-MSCs possessed multilineage differentiation potential. SP-B transfection into UC-MSCs strengthened the effects of UC-MSCs on lung function repair in LPSinduced ARDS. UC-MSCs and UC-MSCs-SP-B attenuated cellular infiltration. Additionally, UC-MSCs and UC-MSCs-SP-B inhibited the inflammatory response by promoting M2-like polarization, as well as reduced Th17 differentiation and promoted Treg differentiation.

Conclusion: UC-MSCs in combination with SP-B, alleviates inflammatory reaction in ARDS by regulating macrophage polarization.

\section{INTRODUCTION}

Acute respiratory distress syndrome (ARDS) is a severe condition from acute lung injury (ALI) ${ }^{1}$ and is a respiratory failure disorder due to hypoxemia, with extremely high morbidity and mortality in critical care. ${ }^{2}$ It accounts for approximately 75,000 deaths annually in America. ${ }^{3}$ Pulmonary infection is the primary etiology of ARDS, in which, especially, lipopolysaccharide (LPS) in Gramnegative bacillus increases the permeability of the alveolar-capillary barrier, thereby leading to non-cardiogenic pulmonary edema. ${ }^{4}$ The inflammatory cascading reaction that is dominated by macrophages and neutrophils is the main mechanism in the pathological process of ARDS. ${ }^{5,6}$ Mass accumulation and infiltration of inflammatory cells in the lungs contribute to excessive inflammatory cytokine release and anti-inflammatory cytokine reduction with a consequence of inflammatory disequilibrium. ${ }^{7}$ Additionally, macrophages are considered indispensable mediators in ALI. ${ }^{8}$ In the lung microenvironment, the alveolar macrophages are polarized into two subpopulations, including M1 and M2 phenotype macrophages. ${ }^{9}$ M1-like polarization contributes to the pro-inflammatory reaction of host defense, whereas M2-like polarization exerts an important function in anti-inflammatory response and tissue remodeling. ${ }^{10}$ Therefore, alveolar macrophage polarization is critical for inflammatory equilibrium in the lungs.

Mesenchymalstemcells(MSCs)possess astrong therapeutic potential and exist in wide types of tissues. ${ }^{11,12}$ Promising features, including pluripotency and immune properties of hypo-immunogenicity, make MSCs superior candidates for cell therapies. ${ }^{13}$ Presently, MSC transplantation has been used in refractory pulmonary disease studies, including bronchopulmonary dysplasia ${ }^{14}$, pulmonary fibrosis ${ }^{15}$, and ARDS. ${ }^{16}$ Compared with other MSCs, umbilical cord-derived MSCs (UC-MSCs) show stronger abilities in tissue damage repair, immunoregulation, and differentiation, as well as

Corresponding author: Minshu Zou, Department of Pediatrics, General Hospital of Central Theater Command of Chinese People's Liberation Army, Wuhan, China e-mail: zouminshu1234@163.com

Received: September 06, 2021 Accepted: November 25, 2021 Available Online Date: March, 14, 2022 • DOI: 10.4274/balkanmedj.galenos.2021.2021-9-8

Available at www.balkanmedicaljournal.org

ORCID iDs of the authors: H.X 0000-0001-6033-991X; G.N. 0000-0002-6185-4881; T.Y. 0000-0002-7534-5885; C.S. 0000-0001-5174-0146; D.D. 0000-0002-56141502; M.Z. 0000-0003-0484-1280.

Cite this article as:

Xu H, Nie G, Yin T, Shao C, Ding D, Zou M. Umbilical Cord-derived Mesenchymal Stem Cells with Surfactant Protein B Alleviates Inflammatory Response in Acute Respiratory Distress Syndrome by Regulating Macrophage Polarization. Balkan Med J.; 2022; 39(2):130-9.

Copyright@Author(s) - Available online at http://balkanmedicaljournal.org/ 
higher gene transfection efficiency. ${ }^{17}$ Surfactant protein B (SP-B) is a key protein in pulmonary surfactant and functions in maintaining mammalian breathing ${ }^{18}$ and is required to maintain lung function, as genetic SP-B knockdown leads to respiratory failure in newborns ${ }^{19}$ and SP-B knockout mice. ${ }^{20}$ Animal-derived lung surfactants that contain native SP-B have been reported to improve outcomes in patients with RDS having surfactant deficiency. ${ }^{21}$

We hypothesized that SP-B-transfected MSCs, which retain cell activity and various physiological effects, may yield stronger therapeutic effects on ARDS after transplantation into the lung. Therefore, this study aimed to transplant UC-MSCs transfected with SP-B into the lung of ARDS mice. By analyzing the pathological changes and inflammatory response of the lung tissue, the role of SP-B transfected UC-MSCs in ARDS was explored.

\section{MATERIALS AND METHODS}

\section{Isolation of UC-MSCs}

UC tissues $(6-9 \mathrm{~cm})$ were taken from pregnant women with fullterm deliveries. This study was approved by the Ethics Committee of General Hospital of Central Theater Command of Chinese People's Liberation Army (Hubei, China) (approval number: KY2019-023). Informed consent was signed by all participants. The tissues of $1 \mathrm{~mm}^{3}$ were washed with phosphate-buffered saline (PBS), digested in $0.1 \%$ collagenase II (Gibco, USA) that contain $30 \mathrm{U} / \mathrm{ml}$ DNase I for $1.5 \mathrm{~h}$, and treated with $0.125 \%$ trypsin (Gibco) for $1 \mathrm{~h}$. After terminating the trypsin activity, the mixture was filtered through a $100-\mu \mathrm{m}$ cell strainer. Cells were then washed and cultured in Dulbecco's Modified Eagle Medium/Nutrient Mixture F-12 (DMEM/F12) (1:1) (Gibco) that contain $100 \mu \mathrm{g} / \mathrm{ml}$ of penicillin, 10\% fetal bovine serum (FBS) (Gibco), and $10 \mu \mathrm{g} /$ $\mathrm{ml}$ of streptomycin (Sigma-Aldrich) at $37^{\circ} \mathrm{C}$ with $5 \% \mathrm{CO}_{2}$. The adherent cells were incubated until confluence.

\section{Flow Cytometry}

Flow cytometry was applied to determine the presence of specific surface antigens of MSCs. Briefly, 1 x $10^{4}$ UC-MSCs that were suspended in $500 \mu \mathrm{l}$ staining buffer with $1 \%$ FBS were cultured for $30 \mathrm{~min}$ at $4{ }^{\circ} \mathrm{C}$. Afterward, cells were stained with the phycoerythrin-conjugated monoclonal antibodies against CD44, CD29, CD34, and CD45 cell surface markers. All primary antibodies were obtained from Becton Dickinson (CA, USA). CytoFLEX Flow Cytometer (Beckman Coulter) that is equipped with CellQuest software (Becton Dickinson) was used to analyze the results.

\section{Osteogenic Differentiation}

UC-MSCs of passage 5-6 were incubated in the osteogenic differentiation culture medium containing DMEM/F12 (1:1), $100 \mu \mathrm{g} / \mathrm{ml}$ of penicillin, $10 \% \mathrm{FBS}, 60 \mu \mathrm{M}$ of ascorbic acid, 10 $\mu \mathrm{g} / \mathrm{ml}$ of streptomycin, $10 \mathrm{nM}$ of dexamethasone, and $10 \mathrm{mM}$ of $\beta$-glycerophosphate disodium (Sigma) ${ }^{22}$ for 21 days. The medium was changed every 3 days. The staining was performed using Alizarin red S staining (Sigma). Mineralization during osteogenesis was monitored.

\section{Adipogenic Differentiation}

UC-MSCs of passage 5-6 were incubated in the adipogenic differentiation medium containing DMEM/F12 (1:1), $100 \mu \mathrm{g} /$ $\mathrm{ml}$ of penicillin, $10 \% \mathrm{FBS}, 50 \mathrm{mM}$ of indomethacin, $10 \mu \mathrm{g} / \mathrm{ml}$ of streptomycin, $200 \mathrm{nM}$ of insulin, $100 \mathrm{nM}$ of dexamethasone, and $0.5 \mathrm{mM}$ of isobutyl-methylxanthine. Cells were seeded in 6-well plates at $2 \times 10^{4}$ cells $/ \mathrm{cm}^{2}$. After 21 days, cells were stained with Oil Red O.

\section{Plasmid Construction and Transfection}

The whole coding region of SP-B was ligated into the pIRES2enhanced green fluorescent protein (EGFP) plasmid at specific restriction sites (BamHI and HindIII). The target fragment sequence was tested by sequencing. UC-MSCs were cultured up to $70 \%$ confluence and then transfected with pIRES2-EGFP-SP-B recombinant plasmid using Lipofectamine 3000 (Invitrogen). Cells were cultured in a selection medium that is supplemented with 400 $\mu \mathrm{g} / \mathrm{ml}$ of geneticin after $48 \mathrm{~h}$. Stable clones were screened. Western blotting was used to confirm the efficiency.

\section{Western Blotting}

Radioimmunoprecipitation assay buffer (Invitrogen) was employed to extract the protein from the transfected UC-MSCs. Protein was separated by $10 \%$ sodium dodecyl sulfate-polyacrylamide gel electrophoresis and then transferred to polyvinylidene difluoride membranes. The membranes were incubated with primary antibodies SP-B (ab271345) and glyceraldehyde 3-phosphate dehydrogenase (ab181602) overnight at $4{ }^{\circ} \mathrm{C}$ after blocking with $5 \%$ skim milk. Appropriate secondary antibodies were then added for $1 \mathrm{~h}$ of incubation at $4^{\circ} \mathrm{C}$. Blot bands were determined with enhanced chemiluminescence reagent (Amersham, USA) and analyzed with Image J software.

\section{Experimental Animal}

Male BALB/c mice (8-week-old; Vital River Co. Ltd, Beijing, China) were raised under controlled conditions $\left(22{ }^{\circ} \mathrm{C}-26{ }^{\circ} \mathrm{C}\right.$; $12 \mathrm{~h}$ light/dark cycle). Animal experiments were approved by the Animal Ethics Committee of General Hospital of Central Theater Command of Chinese People's Liberation Army (Hubei, China) (approval number: DWLL2019-011).

Forty-two mice were evenly divided into six groups as follows: sham (intratracheally received normal saline); UC-MSCs (intratracheally received normal saline plus UC-MSCs); UCMSCs-SP-B (intratracheally received normal saline plus UCMSCs transfected with pIRES2-EGFP-SP-B); LPS (intratracheally received LPS); LPS + UC-MSCs-vector (intratracheally received LPS plus UC-MSCs transfected with empty plasmid), and LPS + UC-MSCs-SP-B (intratracheally received LPS plus UC-MSCs transfected with pIRES2-EGFP-SP-B).

\section{Experimental Model}

BALB/c mice were administrated with LPS. ${ }^{23}$ Animals were anesthetized via an intraperitoneal injection of pentobarbital sodium $(60 \mathrm{mg} / \mathrm{kg})$ before trachea exposure. After the anesthesia, 
mice were intratracheally injected with LPS (O55:B5; $4 \mathrm{mg}$ / $\mathrm{kg}$; Sigma) in $100 \mu \mathrm{l}$ of PBS or normal saline $(0.1 \mathrm{ml} / \mathrm{mouse})$ as control through a 20-gage catheter. After $6 \mathrm{~h}, 1 \times 10^{6} \mathrm{UC}$-MSCs or UC-MSCs transfected with SP-B in $100 \mu \mathrm{l}$ of PBS were intratracheally injected into the mice. After $72 \mathrm{~h}$, the mice were euthanized by cervical dislocation under isoflurane. Lung tissues and bronchoalveolar lavage fluids (BALFs) were collected.

\section{Histology Analysis}

Lung tissues from each group were excised $72 \mathrm{~h}$ posttransplantation and fixed in $10 \%$ formalin under a pressure of 15 $\mathrm{cm} \mathrm{H}_{2} \mathrm{O}$. After fixation for $24 \mathrm{~h}$, tissues were embedded in paraffin. Next, 5 - $\mu \mathrm{m}$-thick specimens were deparaffinized and then stained with hematoxylin and eosin. Lung injury degree was observed with a microscope and semi-quantified according to a previously published lung injury scoring system. ${ }^{24}$

\section{Wet/dry (W/D) Ratio}

Lung tissues were stored in a dry plastic plate, and the wet weight was immediately weighed with an electronic scale. The tissues were dried in an oven for $48 \mathrm{~h}$ at $60{ }^{\circ} \mathrm{C}$ and the dry weight was weighed. The $\mathrm{W} / \mathrm{D}$ ratio indicated the ratio of the wet weight to the dry weight. ${ }^{25}$

\section{Arterial Blood Gas}

As documented ${ }^{26}$, mice were anesthetized with pentobarbital sodium $72 \mathrm{~h}$ post-transplantation. All mice maintained spontaneous breathing at the time of the experiment. Blood was taken from the celiac artery. An ABL90 FLEX analyzer (Radiometer, Denmark) was used to analyze oxygen partial pressure $\left(\mathrm{pO}_{2}\right)$ and saturation. The $\mathrm{pO}_{2}$ / fraction of inspired oxygen $\left(\mathrm{FiO}_{2}\right)$ ratio was calculated.

\section{Measurement of BALF}

Lung tissues were washed with $0.35 \mathrm{ml}$ PBS for BALF sample collections, and BALF samples were centrifuged at $300 \mathrm{~g}$ for $10 \mathrm{~min}$ at $4{ }^{\circ} \mathrm{C}$. Inflammatory cytokines were measured in the supernatants. Total protein concentration was assessed with the bicinchoninic acid assays (Sigma). The precipitated cells were suspended in PBS. Cell counting was performed with a hematocytometer (Countstar IC1000). The number of neutrophils was calculated from the remaining cell suspensions, which were stained with Giemsa.

\section{Enzyme-linked Immunoassay (ELISA)}

The concentrations of interleukin (IL)-1 $\beta$ (Cat.EMC001b), IL10 (Cat.EMC005), IL-13 (Cat.EMC124), tumor necrosis factor $\alpha$ $(\mathrm{TNF} \alpha)(\mathrm{Cat} . \mathrm{EMC} 102 \mathrm{a})$, transforming growth factor $(\mathrm{TGF}-\beta)(\mathrm{Cat}$. F2686-B), and prostaglandin E2 (PGE2) (Cat.F9428-B) in BALF were measured using the ELISA kits (Neo-Bioscience, Shanghai; Hufeng Chemical, Shanghai) following the manufacturer's instructions.

\section{Macrophage Phenotype Analysis}

Entire lung tissues were collected, chipped, and cultured on a shaker at $260 \mathrm{rpm}$ for $1 \mathrm{~h}$. The mixture was filtered through a
40- $\mu \mathrm{m}$ cell strainer to remove the nondigested fragment. Next, 1 $\mathrm{ml}$ of FBS was added to the cell suspension, and the mixture was centrifugated at $220 \mathrm{~g}$ for $10 \mathrm{~min}$. The collected precipitates were resuspended, and red blood cells were discarded with lysis buffer. Afterward, the samples were washed with PBS containing 1\% FBS. Cells were cultured with antibody CD16/CD32 (Cat.553141; Mouse BD Fc Block) for $15 \mathrm{~min}$ at $4^{\circ} \mathrm{C}$ and then washed with PBS. Fixable viability stain 620 (Cat.564996; BD Pharmingen) was incubated with the cell suspension for $20 \mathrm{~min}$ at $18{ }^{\circ} \mathrm{C}$. After washing, cells were then stained with CD11b (Cat.553310), CD11c (Cat. 558079), F4/80 (Cat. 565410), CD45 (Cat. 557659), and CD206 (Cat. 564996) for $1 \mathrm{~h}$ at $4{ }^{\circ} \mathrm{C}$. Flow cytometry (Accuri C6, BD) was used to detect the single-cell suspension containing $10^{6}$ $10^{8}$ cells. T-regulatory (Treg) $\left(\right.$ Foxp $\left.3^{+} / \mathrm{CD} 25^{+}\right)$and Th17 $\left(\mathrm{IL}-17^{+} /\right.$ $\mathrm{CD}^{+}$) were stained with antibodies, including anti-Foxp3-APC and anti-IL-17A-perCP, to detect T cell and T-helper 17 (Th17) cell differentiation. ${ }^{27}$ All fluorescent-labeled antibodies, intracellular staining reagents, and FcR blockers for this assay were purchased from BioLegend (BioLegend, USA) or eBioscience (eBioscience, USA). Flow cytometry data were analyzed using FlowJo software (BD Biosciences, USA).

\section{Statistical Analysis}

Statistical analysis was performed using the Statistical Package for the Social Sciences version 21.0 (Chicago, IL, USA). Values are expressed as the means \pm standard deviation. One-way analysis of variance followed by Tukey's post-comparison test or t-test was applied to analyze the differences between groups. The normal distribution of data was tested using the Shapiro-Wilk test. The Mann-Whitney U test was used for non-normally distributed data. A $p$-value of $<0.05$ was statistically significant. A sample size of seven cases for each group was required to detect at least $50 \%$ difference between the control and test groups, with a power of $85 \%$ at the $1.25 \%$ significance level.

\section{RESULTS}

\section{Identification of MSC Characteristics}

First, the antigenic profile of isolated UC-MSCs was determined according to minimal criteria for defining pluripotent mesenchymal stromal/stem cells. ${ }^{28}$ The population of UC-MSCs highly expressed the MSCs markers, CD44 and CD29, rather than the hematopoietic markers, CD34 and CD45 (Figure 1A-1D). Next, UC-MSCs were induced to differentiate into osteoblasts and adipocytes in a selective culture medium. As shown in Figure 1E, Alizarin Red Staining of UC-MSCs showed large calcium phosphate deposits in the osteogenic induction medium. Additionally, UC-MSCs showed intracellular lipid droplets after adipogenic differentiation induction. These findings suggested that isolated UC-MSCs possess multilineage differentiation potential. We then transfected pIRES2-EGFP-SP-B into UC-MSCs and verified SP-B expression upregulation after transfection $(P=0.003)$ (Figure $1 \mathrm{~F})$. 
a

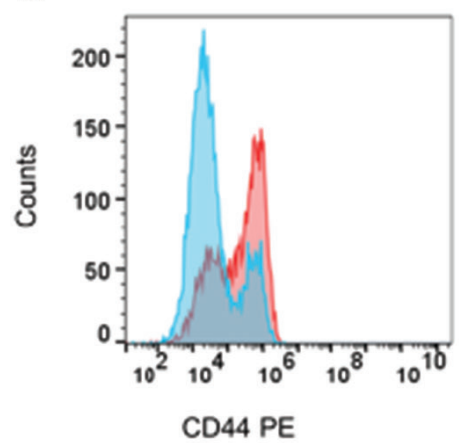

e

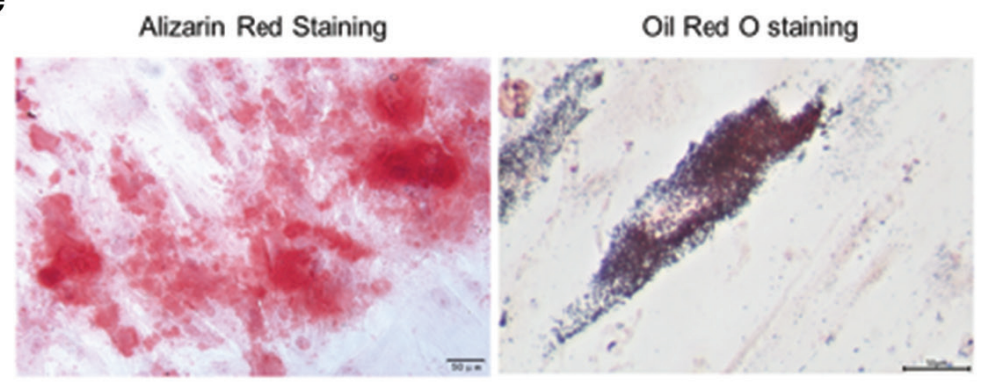

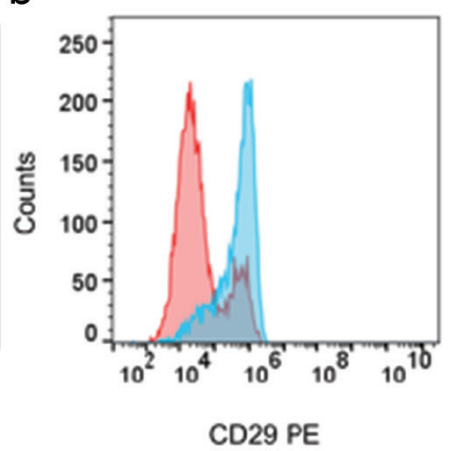

C

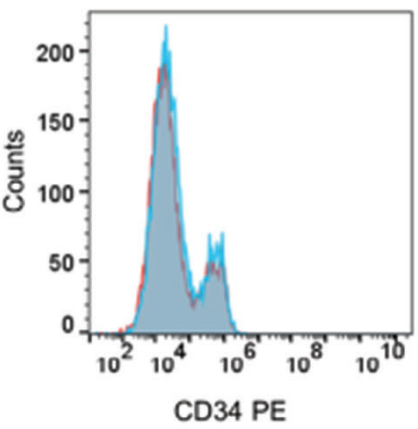

f d

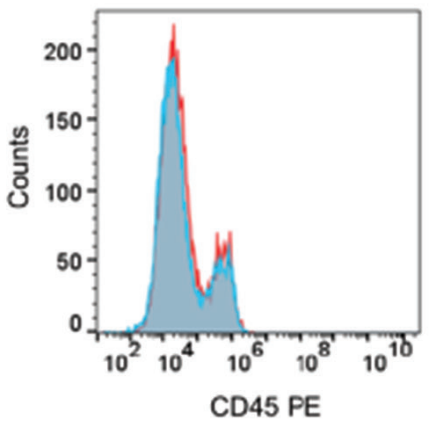

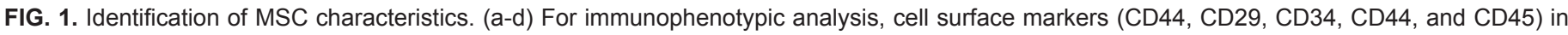

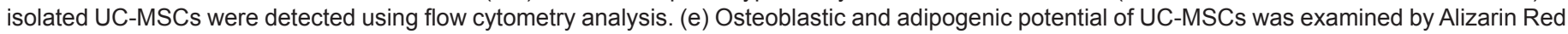

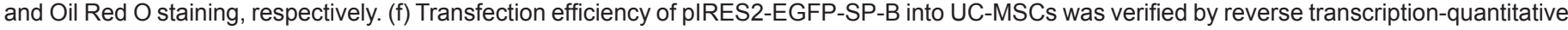
polymerase chain reaction. ${ }^{* *} P<0.01$.

\section{SP-B Strengthens the Protection of UC-MSCs Against LPS- stimulated ARDS}

The therapeutic effects of UC-MSCs were examined. Histological changes in the lung were observed by hematoxylin and eosin staining. No significant difference was found in the histologic change among sham, UC-MSCs, and UC-MSCs-SP-B groups (Figure 2A). Normal alveolar and interstitial tissue structures were destroyed, and the inflammatory infiltration was serious in the LPS group, whereas these changes were markedly attenuated after UC-MSCs transplantation together with SP-B transfection. LPS increased lung injury score in mice (vs. sham group: $P=$ 0.000). UC-MSCs-SP (vs. LPS group, $P=0.009$ ) and UC-MSCsSP-B (vs. LPS + UC-MSCs-vector group, $P=0.017$ ) markedly reduced lung injury score (Figure 2B). The effect of UC-MSCs with SP-B transfection on pulmonary function was evaluated by measuring the W/D ratio and arterial blood gases. Data showed that the mice in LPS + UC-MSCs (vs. LPS group: $P=0.018$ ) and LPS + UC-MSCs-SP-B (group vs. LPS + UC-MSCs-vector group: $P=0.003$ ) groups had lower $\mathrm{W} / \mathrm{D}$ ratio of 6.0 and 4.2 , respectively, than 8.0 in LPS (Figure 2C), which suggest that UCMSCs either alone or combined with SP-B attenuates the degree of LPS-induced lung edema. LPS also reduced the $\mathrm{pO} 2 / \mathrm{FiO} 2$ ratio (vs. sham group: $P=0.000$ ), whereas UC-MSCs (vs. LPS group: $P$
$=0.008$ ) and UC-MSCs-SP-B (vs. LPS + UC-MSCs-vector group: $P=0.017$ ) markedly restored the $\mathrm{pO}_{2} / \mathrm{FiO}_{2}$ ratio (Figure $2 \mathrm{D}$ ), which demonstrated lung function improvement. Overall, SP-B transfection into UC-MSCs strengthens the protective effects of UC-MSCs against LPS-stimulated ARDS.

\section{UC-MSCs and UC-MSCs-SP-B Decreases the Degree of BALF Changes}

Cell counting and protein level in BALF were measured for further analysis of lung damage and inflammation. Total protein level was elevated in LPS group (vs. sham group: $P=0.000$ ) but reduced in LPS + UC-MSCs-vector (vs. LPS group: $P=0.012$ ) and LPS + UC-MSCs-SP-B groups (vs. LPS + UC-MSCs-vector group: $P=$ 0.029) (Figure 3A). Cell number was increased in LPS group (vs. sham group: $P=0.000$ ) but reduced in LPS + UC-MSCs-vector (vs. LPS group: $P=0.015$ ) and LPS + UC-MSCs-SP-B groups (vs. LPS + UC-MSCs-vector group: $P=0.008$ ) (Figure 3B). Additionally, LPS increased the neutrophils in BALF (vs. sham group: $P=0.000$ ), whereas UC-MSCs (vs. LPS group: $P=0.002$ ) or UC-MSCs-SP-B (vs. LPS + UC-MSCs-vector group: $P=0.002$ ) decreased this number (Figure $3 \mathrm{C}$ ). These findings suggested that UC-MSCs either alone or combined with SP-B not only improve lung injury in ARDS but attenuate cellular infiltration. 
a

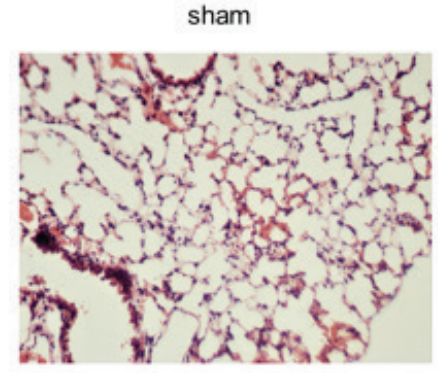

LPS

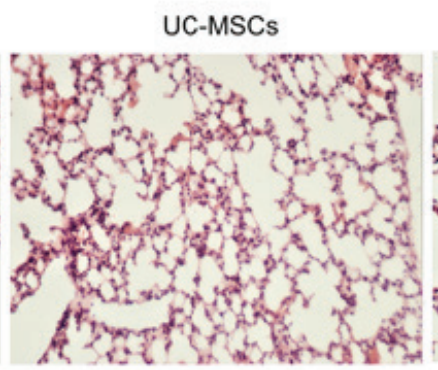

LPS+UC-MSCs-vector
UC-MSCs-SP-B

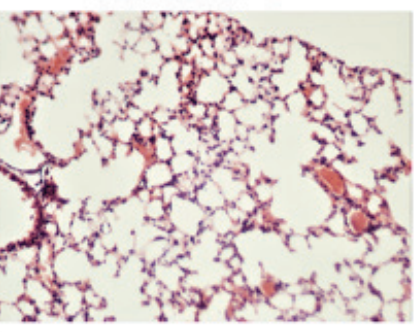

LPS+UC-MSCs-SP-B

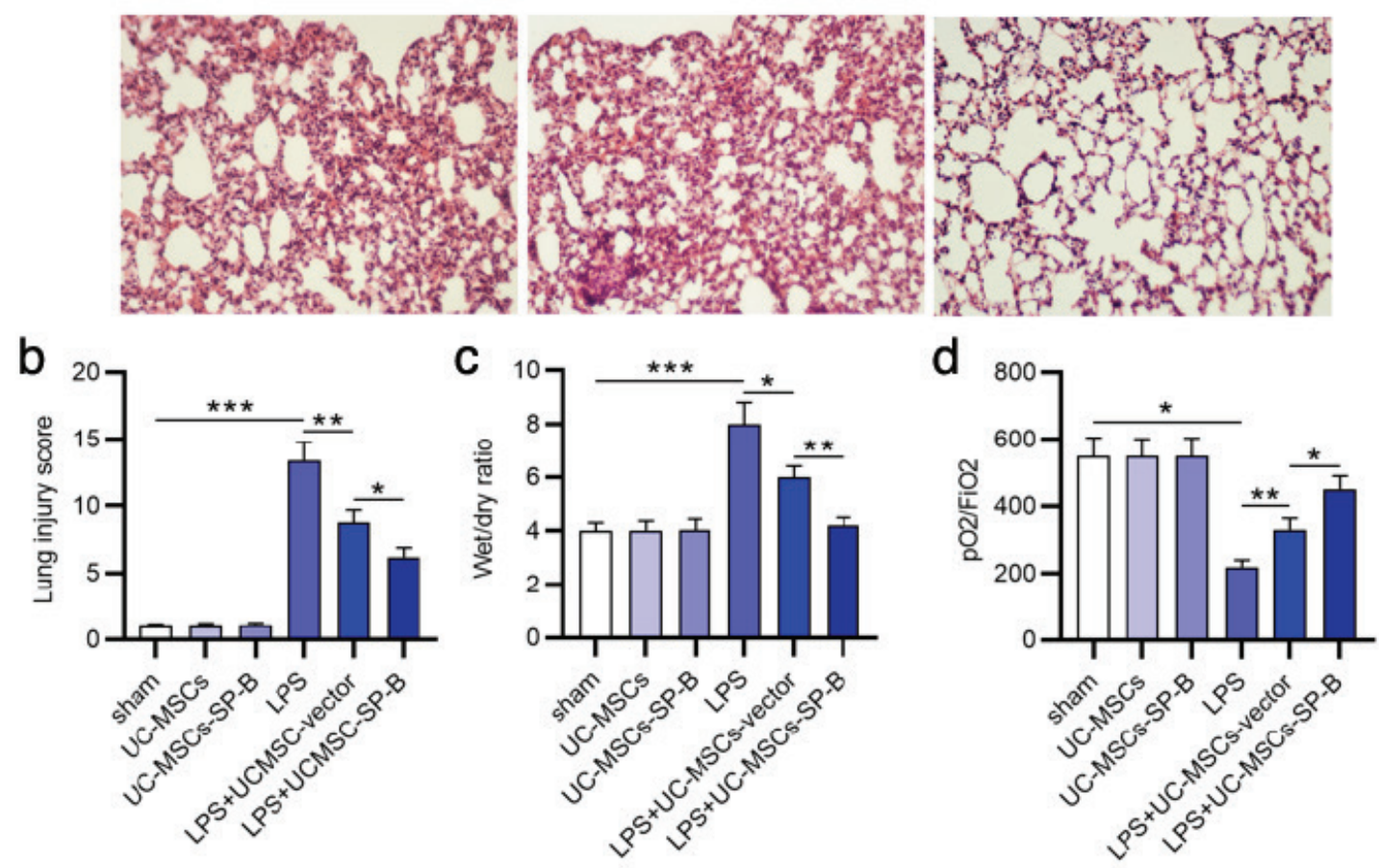

FIG. 2. SP-B strengthens the protection of UC-MSCs against LPS-stimulated ARDS. (a) Lung histological changes in each group were observed by hematoxylin and eosin staining. (b) Evaluation of lung injury scores in each group. (c) W/D ratio analysis. (d) $\mathrm{The}^{\mathrm{pO}} / \mathrm{FiO}_{2}$ ratio analysis. ${ }^{*} P<0.05$, ${ }^{\star *} P<0.01,{ }^{* \star *} P<0.001 . \mathrm{N}=7$.

\section{SP-B Strengthens the Promotive Effect of UC-MSCs on M2 Polarization}

The impact of UC-MSCs on alveolar macrophage polarization in LPS mice was assessed using flow cytometry analysis. $\mathrm{CD} 11 \mathrm{c}^{+} \mathrm{CD} 206^{-}$indicates an M1-like polarization and CD11 $\mathrm{CD}_{206^{+}}$indicates an M2-like polarization. As illustrated in Figure $4 \mathrm{~A}-4 \mathrm{C}$, percentages of both $\mathrm{M} 1$ and M2 macrophages were elevated in LPS mice compared to sham mice (vs. sham group: $P=0.000$ ). However, LPS + UC-MSCs-vector (vs. LPS group: $P=0.006$ ) and LPS + UC-MSCs-SP-B (vs. LPS + UC-MSCsvector group: $P=0.004$ ) groups showed lower percentage of M1 and higher percentage of M2 than in LPS group. Changes in the $\mathrm{M} 2 / \mathrm{M} 1$ ratio revealed a dominant M1 polarization compared to M2 polarization in the LPS group (vs. sham group: $P=0.017$ ), whereas UC-MSCs (vs. LPS group: $P=0.001$ ) or UC-MSCsSP-B (vs. LPS + UC-MSCs-vector group: $P=0.002$ ) significantly promoted macrophage polarization toward $\mathrm{M} 2$, as shown by increased M2/M1 ratio (Figure 4D). ELISA was used to measure the concentrations of pro-inflammatory cytokines (IL-1 $\beta$ and TNF $\alpha$ ) and anti-inflammatory chemokines (IL-10, IL-13, TGF- $\beta$ and PGE2) in BALF to analyze inflammatory regulation mediated by UC-MSCs. The increased levels of LPS-induced IL-1 $\beta$ and TNF $\alpha$ were significantly reversed by UC-MSCs (vs. LPS group: $P$ $=0.006$ and $P=0.006$, respectively) or UC-MSCs-SP-B (vs. LPS + UC-MSCs-vector group: $P=0.001$ and $P=0.003$, respectively) (Figure 4E, 4F). Additionally, in parallel, the levels of IL-10, IL13, TGF- $\beta$, and PGE2 were increased in LPS (vs. sham group: $P=$ $0.004, P=0.001, P=0.001$, and $P=0.001$, respectively), LPS + UC-MSCs-vector (vs. LPS group: $P=0.010, P=0.001, P=0.001$, and $P=0.001$, respectively), and LPS + UC-MSCs-SP-B groups (vs. LPS + UC-MSCs-vector group: $P=0.013, P=0.015, P=$ 0.010 , and $P=0.008$, respectively) (Figure 4G-4I). Overall, UC- 

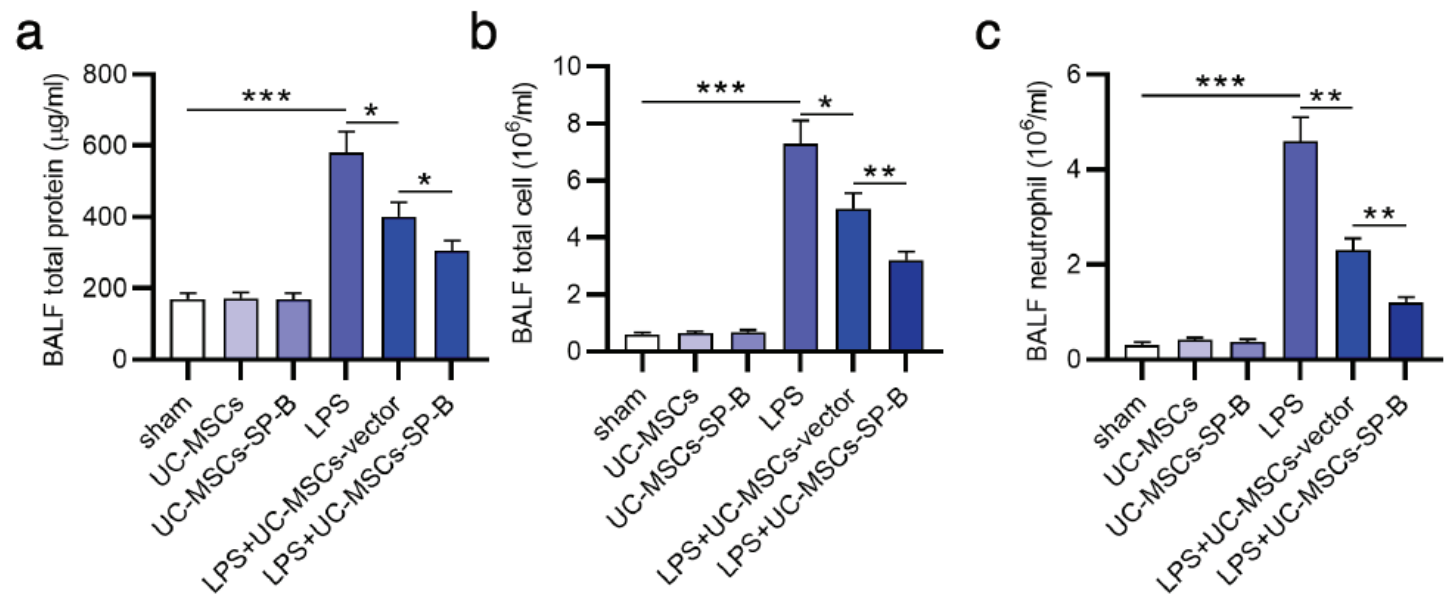

FIG. 3. UC-MSCs and UC-MSCs-SP-B decreases the degree of BALF changes. (a) Total protein level in BALF. (b) Cell counting in BALF. (c) Neutrophil counting in BALF. ${ }^{*} P<0.05,{ }^{, *} P<0.01,{ }^{* * *} P<0.001 . N=7$.

MSCs and UC-MSCs-SP-B inhibit inflammation by promoting M2-like polarization in ARDS.

\section{UC-MSCs-SP-B Reduces Th17 Differentiation and Promotes Treg Differentiation}

The effects of UC-MSCs-SP-B on the regulation of T cell and Th17 were further examined. As expected, a markedly increased number of $\mathrm{IL}-17^{+} / \mathrm{CD} 4^{+}$cells and reduced Foxp $3^{+} / \mathrm{CD} 25^{+}$after the addition of LPS was found (vs. sham group: $P=0.001$ and $P=0.001$, respectively). Notably, UC-MSCs (vs. LPS group: $P=0.013$ and $P$ $=0.001$, respectively) or UC-MSCs-SP-B (vs. LPS + UC-MSCsvector group: $P=0.029$ and $P=0.017$, respectively) inhibited Th17 differentiation, whereas promoted Treg differentiation (Figure 5A, 5B). Therefore, UC-MSCs-SP-B displays a key role in modulating the inflammatory differentiation of $\mathrm{T}$ cells.

\section{DISCUSSION}

ARDS is related to diffuse epithelial injury that is induced by an impaired alveolar-capillary barrier with consequently raised permeability, pulmonary edema, and neutrophil accumulation. During this process, persistent inflammation and plasma protein loss contribute to lung dysfunction. Insufficient effective treatment for ARDS is associated with the multifactorial etiology of this disorder. $^{29,30}$ MSCs could be a promising candidate for cell therapy in inflammatory pulmonary diseases. Evidence has shown beneficial effects from the transplant of bone marrow or umbilical cord-derived MSCs in lung injury treatment. ${ }^{31}$ The effects of UCMSCs in combination with SP-B in ARDS were preliminarily explored.

Inflammation is a critical pathophysiological event in ARDS, which is a complicated and highly coherent process. ${ }^{32}$ The transition from acute inflammation to chronic inflammation may result in tissue damage and ultimately multiple organ failure. ${ }^{33}$ In the present investigation, LPS, an important component of the gram-negative bacilli cell wall, induces a significant inflammatory response in the BALF of mice. Normal alveolar and interstitial tissue structure were destroyed accompanied by a high lung injury score after LPS instillation. Additionally, LPS aggravated pulmonary edema and neutrophil infiltration. UC-MSCs have more primitive, proliferative, and immunosuppressive characteristics. ${ }^{17}$ UC-MSCs effectively restore protein permeability in ALI and confer more practical and functional advantages than their adult counterparts. ${ }^{34}$ Studies have suggested that UC-MSCs infusion effectively decreases lung inflammation, prevents pulmonary fibrosis, increases blood counts, recovers hematopoiesis, and improves survival in shrews with acute radiation injury. ${ }^{35}$ Moreover, UC-MSC infusion was an effective therapeutic tool for patients with ARDS. ${ }^{36}$ This study revealed that intratracheal infusion of UC-MSCs in combination with SP-B attenuated inflammation and improved lung function in experimental ARDS models.

Resident inflammatory cells-alveolar macrophages are activated after stimulation and produce numerous cytokines, which promote the chemotaxis of neutrophils, monocytes, and lymphocytes, thereby aggravating the inflammatory lung responses. ${ }^{37}$ M1 macrophages potentiate the local inflammatory response by secreting inflammatory mediators, whereas M2 macrophages can inhibit inflammatory damage by releasing anti-inflammatory mediators. Once the pulmonary microenvironment is stimulated, alveolar macrophages are immediately transformed into the M1 phenotype. $^{8,38}$ Our results showed that the M1 phenotype was dominant after LPS stimulation compared to the M2 phenotype. MSCs promote the differentiation of macrophages into M2 and exert an anti-inflammatory effect in neonatal lung injury. ${ }^{39} \mathrm{MSCs}$ treatment alleviates bronchopulmonary dysplasia, improves lung function, and ameliorates pulmonary hypertension by pulmonary macrophage phenotype regulation. ${ }^{40}$ According to previous research, the ratio of pulmonary M1/M2 macrophages is increased 
a

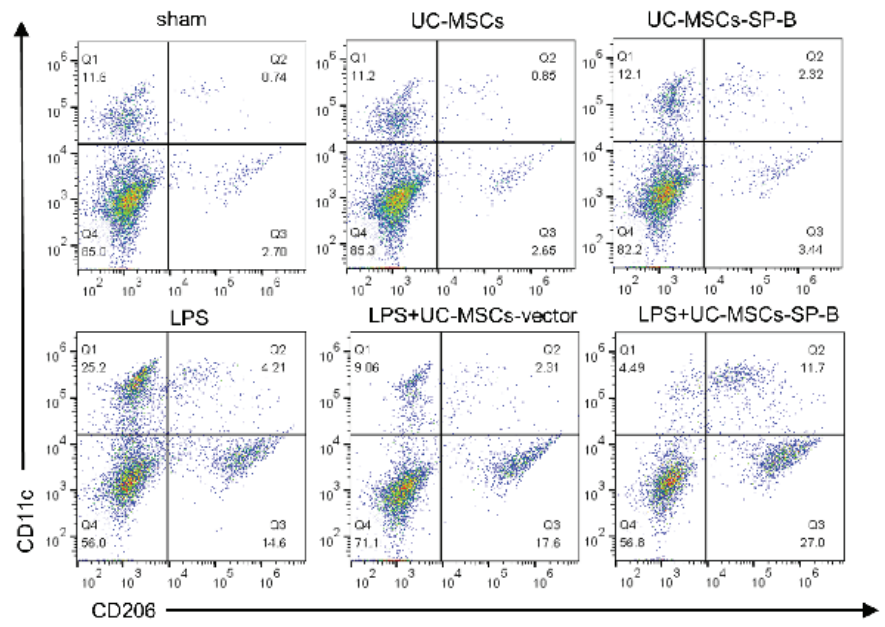

b

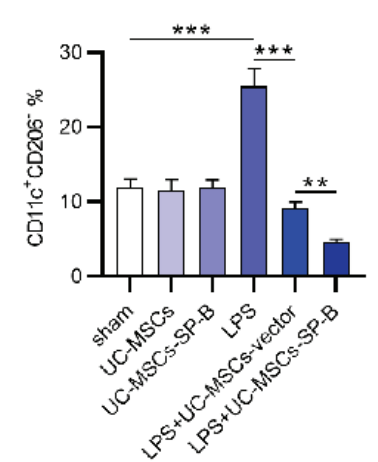

e

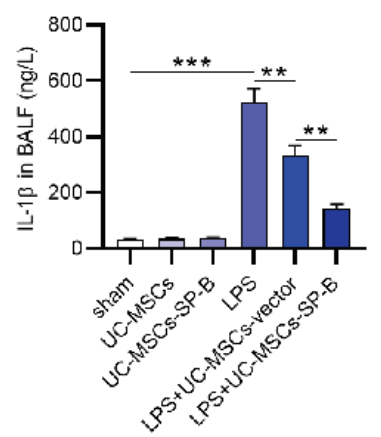

h

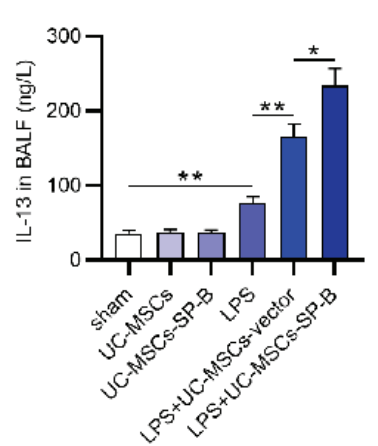

C

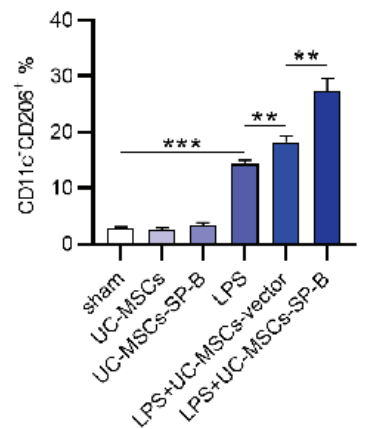

f

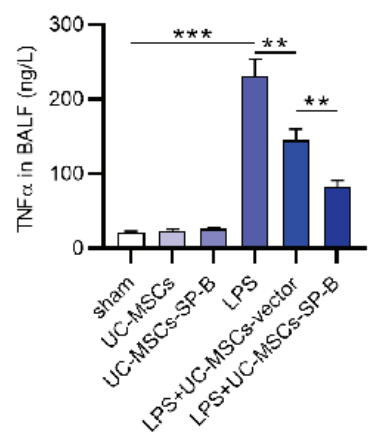

i

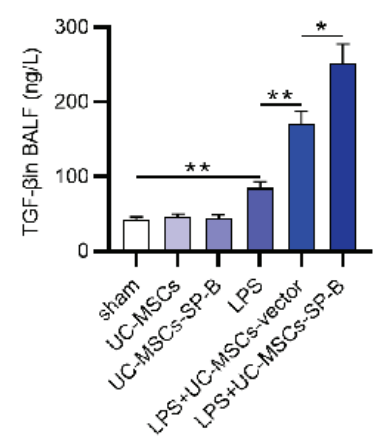

d

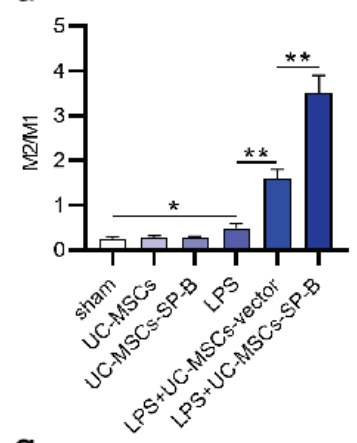

g
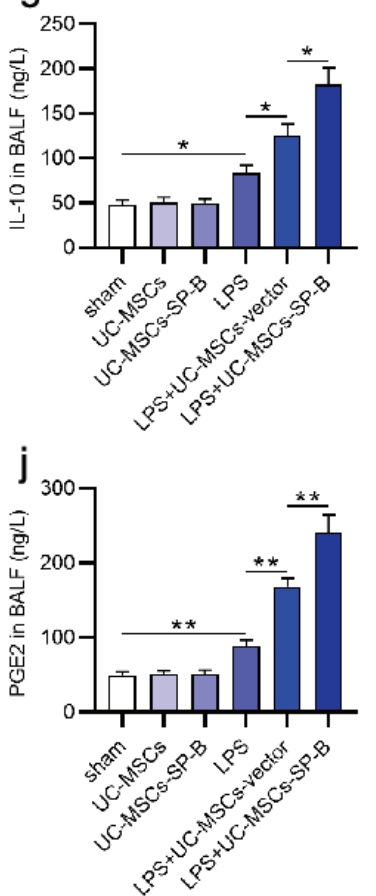

FIG. 4. SP-B strengthens the promotive effect of UC-MSCs on M2 polarization. (a) Polarization of alveolar macrophages using flow cytometry analysis. (b) The change in M1 (CD11 $\left.\mathrm{c}^{+} \mathrm{CD} 206^{-}\right)$polarization. (c) The change in M2 (CD11c-CD206 ${ }^{+}$) polarization. (d) The M2/M1 ratio. (e-j) The concentrations of IL-1 $\beta$, TNFa, IL-10, IL-13, TGF- $\beta$, and PGE2 in BALF were measured by ELISA. ${ }^{*} P<0.05,{ }^{* *} P<0.01,{ }^{* * *} P<0.001 . N=7$. 

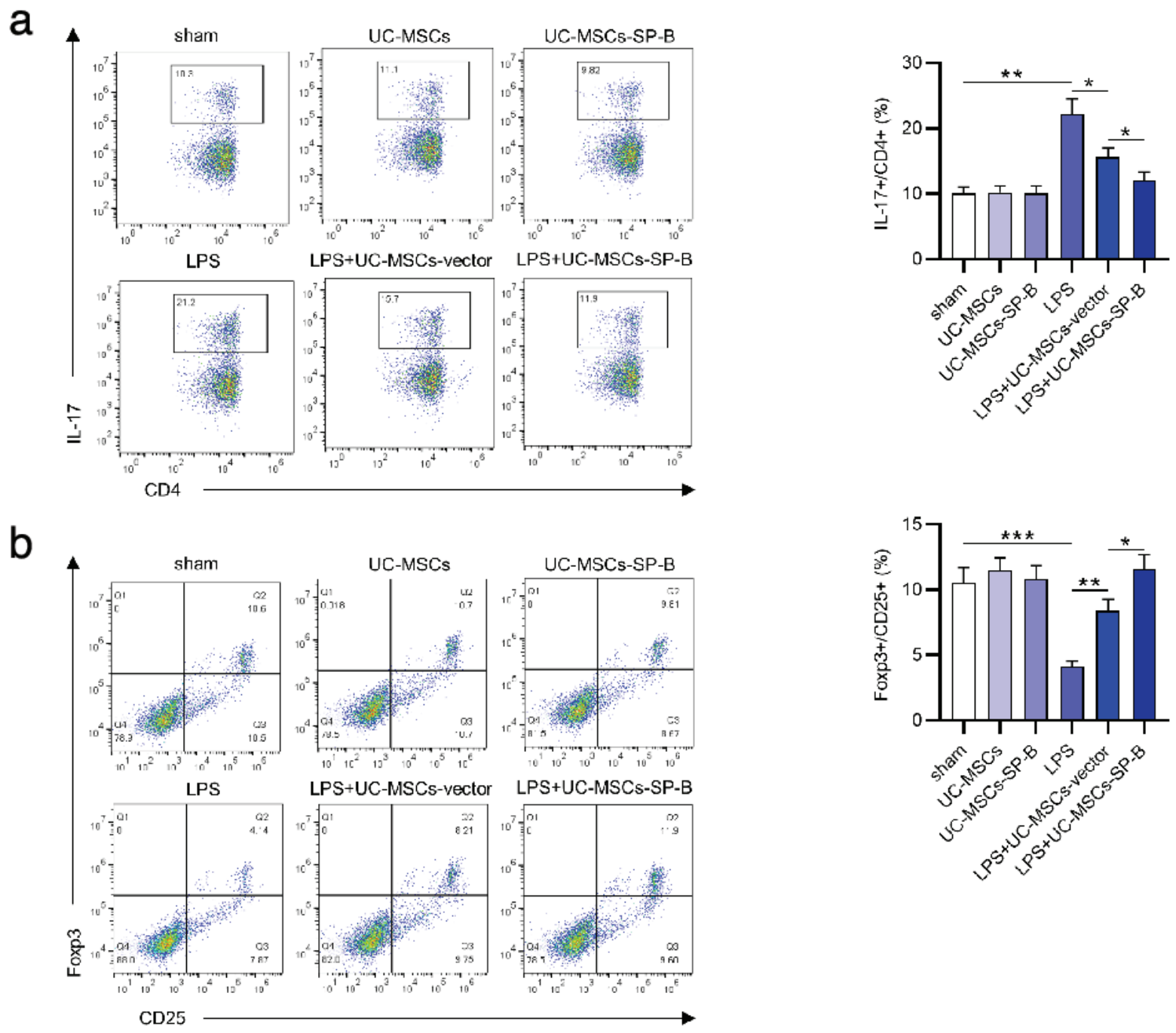

FIG. 5. UC-MSCs reduces Th17 differentiation and promotes Treg differentiation. (a) The percentage of Th17 (IL17 $\left.{ }^{+} \mathrm{CD} 4^{+} \mathrm{T}\right)$ cells was analyzed by flow cytometry. (b) The percentage of Tregs $\left(\right.$ Foxp $3^{+} \mathrm{CD} 25^{+} \mathrm{T}$ ) was analyzed by flow cytometry. ${ }^{*} P<0.05,{ }^{* *} P<0.01,{ }^{* * *} P<0.001 . N=7$.

accompanied by reduced SP-B expression, which indicates lung injury initiation. ${ }^{41}$ Here, after LPS treatment, intratracheal transplantation of either UC-MSCs or UC-MSCs-SP-B suppressed the M1-like polarization and augmented the M2-like polarization in the BALF. This suggested that UC-MSCs transfected with SP-B regulate inflammation in ARDS through macrophage polarization modulation. Moreover, UC-MSCs-SP-B reduced Th17 differentiation and promoted Treg differentiation after ARDS.

SP-B preferentially binds to anionic surfactant lipids that potentiate the capacity of SP-B of facilitating lipid adsorption to the air-water interface. ${ }^{42}$ The SP-B dimer is oligomerized in a circular structure, which mediates the connection between surfactant membranes. ${ }^{43,44}$ SP-B knockdown contributes to lung inflammation, thereby supporting the models that surface force disruption activates proinflammatory signaling. ${ }^{45}$ After SP-B is lost, L-selectin is rapidly produced. L-selectin can mediate lung inflammation through increased leukocyte mobility into the lungs. ${ }^{46}$ STAT-3 activates many genes that are involved in lung protection. After doxycycline withdrawal, STAT-3 is phosphorylated and upregulated, which may indicate a compensatory response to SP-B deficiency. ${ }^{47}$ Additionally, phosphorylation of STAT-3 was reported crucial for repolarization of M1 to M2 type. ${ }^{48}$ Therefore, M1/M2 polarization mechanisms regulated by SP-B may involve multiple molecules and signals, which need further investigations in the future.

Overall, our findings showed that transplantation of UCMSCs transfected with SP-B could potentiate M2 macrophage polarization and further relieve LPS-stimulated lung injury. This demonstrated that the combination of UC-MSCs with SP-B yields significant alleviative effects on ARDS, which may be a promising strategy for ARDS treatment. 
Ethics Committee Approval: This study was approved by the Ethics Committee of General Hospital of Central Theater Command of Chinese People's Liberation Army (Hubei, China) (approval number: KY2019-023).

Data Sharing Statement: The data that support the findings of this study are available from the corresponding author upon reasonable request.

Informed Consent: Informed consent was signed by all participants.

Authorship Contributions: Concept- H.X., M.Z.; Design- H.X., M.Z.; Supervision - H.X., M.Z.; Data Collection and Processing - G.N., T.Y.,C.S., M.Z.; Analysis and/or Interpretation - G.N., C.S., D.D., M.Z.; Literature Review- H.X., D.D., ; Writing - H.X.

Conflict of Interest: No conflict of interest was declared by the authors.

Funding: This work was supported by Health commission of Hubei Province scientific research project (No. WJ2019H094).

\section{REFERENCES}

1. Butt Y, Kurdowska A, Allen TC. Acute Lung Injury: A Clinical and Molecular Review. Arch Pathol Lab Med. 2016;140:345-350. [CrossRef]

2. Han S, Mallampalli RK. The acute respiratory distress syndrome: from mechanism to translation. J Immunol. 2015;194:855-860. [CrossRef]

3. Rubenfeld GD, Caldwell E, Peabody E, et al. Incidence and outcomes of acute lung injury. N Engl J Med. 2005;353:1685-1693. [CrossRef]

4. Zhang K, Wang P, Huang S, et al. Different mechanism of LPS-induced calcium increase in human lung epithelial cell and microvascular endothelial cell: a cell culture study in a model for ARDS. Mol Biol Rep. 2014;41:4253-4259. [CrossRef]

5. Manappallil RG. A Case of Macrophage Activation Syndrome with Acute Respiratory Distress Syndrome. J Clin Diagn Res. 2016;10:Od11-od12. [CrossRef]

6. Gill SE, Yamashita CM, Veldhuizen RA. Lung remodeling associated with recovery from acute lung injury. Cell Tissue Res. 2017;367:495-509. [CrossRef]

7. Short KR, Kroeze EJBV, Fouchier RAM, Kuiken T. Pathogenesis of influenzainduced acute respiratory distress syndrome. Lancet Infect Dis. 2014;14:57-69. [CrossRef]

8. Johnston LK, Rims CR, Gill SE, McGuire JK, Manicone AM. Pulmonary macrophage subpopulations in the induction and resolution of acute lung injury. Am J Respir Cell Mol Biol. 2012;47:417-426. [CrossRef]

9. Varol C, Mildner A, Jung S. Macrophages: development and tissue specialization. Annu Rev Immunol. 2015;33:643-675. [CrossRef]

10. Liu YC, Zou XB, Chai YF, Yao YM. Macrophage polarization in inflammatory diseases. Int J Biol Sci. 2014;10:520-529. [CrossRef]

11. Wang S, Qu X, Zhao RC. Clinical applications of mesenchymal stem cells. J Hematol Oncol. 2012;5:19. [CrossRef]

12. Branch MJ, Hashmani K, Dhillon P, Jones DR, Dua HS, Hopkinson A. Mesenchymal stem cells in the human corneal limbal stroma. Invest Ophthalmol Vis Sci. 2012;53:5109-5116. [CrossRef]

13. Squillaro T, Peluso G, Galderisi U. Galderisi, Clinical Trials With Mesenchymal Stem Cells: An Update. Cell Transplant. 2016;25:829-848. [CrossRef]

14. Braun RK, Chetty C, Balasubramaniam V, et al. Intraperitoneal injection of MSCderived exosomes prevent experimental bronchopulmonary dysplasia. Biochem Biophys Res Commun. 2018;503:2653-2658. [CrossRef]

15. Tzouvelekis A, Toonkel R, Karampitsakos T, et al. Mesenchymal Stem Cells for the Treatment of Idiopathic Pulmonary Fibrosis. Front Med (Lausanne). 2018;5:142. [CrossRef]

16. Day YJ, Chen KH, Chen YL, et al. Preactivated and Disaggregated ShapeChanged Platelets Protected Against Acute Respiratory Distress Syndrome Complicated by Sepsis Through Inflammation Suppression. Shock. 2016;46:575586. [CrossRef]

17. El Omar R, Beroud J, Stoltz JF, Menu P, Velot E, Decot V. Umbilical cord mesenchymal stem cells: the new gold standard for mesenchymal stem cell-based therapies? Tissue Eng Part B Rev. 2014;20:523-544. [CrossRef]

18. Guagliardo R, Herman L, Penders J, et al. Surfactant Protein B Promotes Cytosolic SiRNA Delivery by Adopting a Virus-like Mechanism of Action. ACS Nano. 2021;15:8095-8109. [CrossRef]
19. Nogee LM, Garnier G, Dietz HC, et al. A mutation in the surfactant protein B gene responsible for fatal neonatal respiratory disease in multiple kindreds. J Clin Invest. 1994;93:1860-1863. [CrossRef]

20. Clark JC, Wert SE, Bachurski CJ, et al. Targeted disruption of the surfactant protein B gene disrupts surfactant homeostasis, causing respiratory failure in newborn mice. Proc Natl Acad Sci U S A. 1995;92:7794-7798. [CrossRef]

21. Singh N, Halliday HL, Stevens TP, Suresh G, Soll R, Rojas-Reyes MX. Comparison of animal-derived surfactants for the prevention and treatment of respiratory distress syndrome in preterm infants. Cochrane Database Syst Rev. 2015:Cd010249. [CrossRef]

22. Chen HS, Hsu CY, Chang YC, et al. Benzyl butyl phthalate decreases myogenic differentiation of endometrial mesenchymal stem/stromal cells through miR-137mediated regulation of PITX2. Sci Rep. 2017;7:186. [CrossRef]

23. Pedrazza L, Cunha A, Luft C, Nuñez NK. Mesenchymal stem cells improves survival in LPS-induced acute lung injury acting through inhibition of NETs formation. $J$ Cell Physio. 2017;232:3552-3564. [CrossRef]

24. Matute-Bello G, Downey G, Moore BB, et al. An official American Thoracic Society workshop report: features and measurements of experimental acute lung injury in animals. Am J Respir Cell Mol Biol. 2011;44:725-738. [CrossRef]

25. Chen L, Guo L, Chen F, et al.Transplantation of menstrual blood-derived mesenchymal stem cells (MbMSCs) promotes the regeneration of mechanical injuried endometrium. Am J Transl Res. 2020;12:4941-4954. [CrossRef]

26. Jin M, Sun CY, Pei CQ, Wang L, Zhang PC. Effect of safflor yellow injection on inhibiting lipopolysaccharide-induced pulmonary inflammatory injury in mice. Chin J Integr Med. 2013;19:836-843. [CrossRef]

27. Wang H, Qi F, Dai X, et al.Requirement of B7-H1 in mesenchymal stem cells for immune tolerance to cardiac allografts in combination therapy with rapamycin. Transpl Immunol. 2014;31:65-74. [CrossRef]

28. Dominici M, Le Blanc K, Mueller I, et al. Minimal criteria for defining multipotent mesenchymal stromal cells. The International Society for Cellular Therapy position statement. Cytotherapy. 2006;8:315-317. [CrossRef]

29. Confalonieri M, Salton F, Fabiano F. Acute respiratory distress syndrome. Eur Respir Rev. 2017;26:160116. [CrossRef]

30. Griffiths MJD, McAuley DF, Perkins GD, et al., Guidelines on the management of acute respiratory distress syndrome. BMJ Open Respir Res. 2019;6:e000420. [CrossRef]

31. Moodley Y, Atienza D, Manuelpillai U, et al.Human umbilical cord mesenchymal stem cells reduce fibrosis of bleomycin-induced lung injury. Am J Pathol. 2009;175:303313. [CrossRef]

32. Chen H, Bai C, Wang X. The value of the lipopolysaccharide-induced acute lung injury model in respiratory medicine. Expert Rev Respir Med. 2010;4:773-783. [CrossRef]

33. Spite M, Serhan CN. Novel lipid mediators promote resolution of acute inflammation: impact of aspirin and statins. Circ Res. 2010;107:1170-1184. [CrossRef]

34. Loy H, Kuok DIT, Hui KPY, et al. Therapeutic Implications of Human Umbilical Cord Mesenchymal Stromal Cells in Attenuating Influenza A(H5N1) Virus-Associated Acute Lung Injury. J Infect Dis. 2019;219:186-196. [CrossRef]

35. Guo DB, Zhu XQ, Li QQ, et al. Efficacy and mechanisms underlying the effects of allogeneic umbilical cord mesenchymal stem cell transplantation on acute radiation injury in tree shrews. Cytotechnology. 2018;70:1447-1468. [CrossRef]

36. Lanzoni G, Linetsky E, Correa D, et al. Umbilical cord mesenchymal stem cells for COVID-19 acute respiratory distress syndrome: A double-blind, phase 1/2a, randomized controlled trial. Stem Cells Transl Med. 2021;10:660-673. [CrossRef]

37. Fan EKY, Fan J. Regulation of alveolar macrophage death in acute lung inflammation. Respir Res. 2018;19:50. [CrossRef]

38. Herold S, Gabrielli NM, Vadász I. Novel concepts of acute lung injury and alveolar-capillary barrier dysfunction. Am J Physiol Lung Cell Mol Physiol. 2013;305:L665-L681. [CrossRef]

39. Al-Rubaie A, Wise AF, Sozo F, et al. The therapeutic effect of mesenchymal stem cells on pulmonary myeloid cells following neonatal hyperoxic lung injury in mice. Respir Res. 2018;19:114. [CrossRef]

40. Willis GR, Fernandez-Gonzalez A, Anastas J, et al. Mesenchymal Stromal Cell Exosomes Ameliorate Experimental Bronchopulmonary Dysplasia and Restore Lung Function through Macrophage Immunomodulation. Am J Respir Crit Care Med. 2018;197:104-116. [CrossRef] 
41. Lu HL, Huang XY, Luo YF, Tan WP, Chen PF, Guo YB. Activation of M1 macrophages plays a critical role in the initiation of acute lung injury. Biosci Rep. 2018;38: BSR20171555. [CrossRef]

42. Ingenito EP, Mora R, Mark L. Pivotal role of anionic phospholipids in determining dynamic behavior of lung surfactant. Am J Respir Crit Care Med. 2000;161:831-838. [CrossRef]

43. Olmeda B, García-Álvarez B, Gómez MJ, Martínez-Calle M, Cruz A, Pérez-Gil J.A model for the structure and mechanism of action of pulmonary surfactant protein $B$. FASEB J. 2015;29:4236-4247. [CrossRef]

44. Pérez-Gil J, Casals C, Marsh D. Marsh, Interactions of hydrophobic lung surfactant proteins SP-B and SP-C with dipalmitoylphosphatidylcholine and dipalmitoylphosphatidylglycerol bilayers studied by electron spin resonance spectroscopy. Biochemistry. 1995;34:3964-3971. [CrossRef]
45. Ikegami M, Whitsett JA, Martis PC, Weaver TE. Reversibility of lung inflammation caused by SP-B deficiency. Am J Physiol Lung Cell Mol Physiol. 2005;289:L962-L970. [CrossRef]

46. Choudhury S, Wilson MR, Goddard ME, O’Dea KP, Takata M. Mechanisms of early pulmonary neutrophil sequestration in ventilator-induced lung injury in mice. $\mathrm{Am} \mathrm{J}$ Physiol Lung Cell Mol Physiol. 2004;287:L902-L910. [CrossRef]

47. Hokuto I, Ikegami M, Yoshida M, et al. Stat-3 is required for pulmonary homeostasis during hyperoxia. J Clin Invest. 2004;113:28-37. [CrossRef]

48. Neog MK, Sultana F, Rasool M. Targeting RAW 264.7 macrophages (M1 type) with Withaferin-A decorated mannosylated liposomes induces repolarization via downregulation of NF- $\mathrm{KB}$ and controlled elevation of STAT-3. Int Immunopharmacol. 2018;61:64-73. [CrossRef] 